\title{
An optimal window of platelet reactivity by LTA assay for patients undergoing percutaneous coronary intervention
}

Jing Wang ${ }^{1,2+}$, Jing Wang ${ }^{1 \dagger}$, Zhou Dong ${ }^{1 \dagger}$, Jiazheng $\mathrm{Ma}^{1+}$, Jianzhen Teng ${ }^{1}$, Tong Wang ${ }^{1,3}$, Xiaofeng Zhang ${ }^{1,4}$,

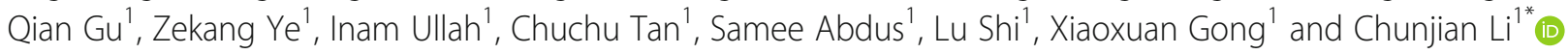

\begin{abstract}
Objective: This study was aimed to determine how platelet reactivity (PR) on dual antiplatelet therapy predicts ischemic and bleeding events in patients underwent percutaneous coronary intervention ( $\mathrm{PCl}$ ).

Design: A total of 2768 patients who had received coronary stent implantation and had taken aspirin $100 \mathrm{mg}$ in combination with clopidogrel $75 \mathrm{mg}$ daily for $>5$ days were consecutively screened and 1885 were enrolled. The recruited patients were followed-up for 12 months. The primary end-point was the net adverse clinical events (NACE) of cardiovascular death, nonfatal myocardial infarction (MI), target vessel revascularization (TVR), stent thrombosis (ST) and any bleeding.

Result: 1709 patients completed the clinical follow-up. By using the receiver operating characteristic (ROC) curve analysis, the optimal cut-off values were found to be 37.5 and $25.5 \%$ respectively in predicting ischemic and bleeding events. Patients were classified into 2 groups according to PR: inside the window group (IW) [adenosine diphosphate (ADP) induced platelet aggregation ( $\left.P L_{A D P}\right)$ 25.5-37.4\%)] and outside the window group (OW) $\left(\mathrm{PL}_{\mathrm{ADP}}<25.5 \%\right.$ or $\left.\geq 37.5 \%\right)$. The incidence of NACE was 16.8 and $23.1 \%$ respectively in the IW and OW group. The hazard ratio of NACE in IW group was significantly lower $[0.69(95 \% \mathrm{Cl}, 0.54-0.89, P=0.004)]$ than that in the OW group during 12-month follow-up.
\end{abstract}

Conclusion: An optimal therapeutic window of $25.5-37.4 \%$ for $\mathrm{PL}_{\mathrm{ADP}}$ predicts the lowest risk of NACE, which could be referred for tailored antiplatelet treatment while using LTA assay.

Trial registration: Trial registration number: ClinicalTrials.gov NCT01968499. Registered 18 October 2013 Retrospectively registered.

Keywords: Light transmittance aggregometry, Platelet reactivity, Percutaneous coronary intervention, Therapeutic window

\footnotetext{
* Correspondence: lijay@njmu.edu.cn

† Jing Wang, Jing Wang, Zhou Dong and Jiazheng Ma contributed equally to this work.

${ }^{1}$ Departments of Cardiology, the First Affiliated Hospital of Nanjing Medical University, 300 Guangzhou Road, Nanjing 210029, Jiangsu, China

Full list of author information is available at the end of the article
}

(C) The Author(s). 2021 Open Access This article is licensed under a Creative Commons Attribution 4.0 International License, which permits use, sharing, adaptation, distribution and reproduction in any medium or format, as long as you give appropriate credit to the original author(s) and the source, provide a link to the Creative Commons licence, and indicate if changes were made. The images or other third party material in this article are included in the article's Creative Commons licence, unless indicated otherwise in a credit line to the material. If material is not included in the article's Creative Commons licence and your intended use is not permitted by statutory regulation or exceeds the permitted use, you will need to obtain permission directly from the copyright holder. To view a copy of this licence, visit http://creativecommons.org/licenses/by/4.0/. The Creative Commons Public Domain Dedication waiver (http://creativecommons.org/publicdomain/zero/1.0/) applies to the data made available in this article, unless otherwise stated in a credit line to the data. 


\section{Introduction}

Dual antiplatelet therapy with aspirin and an adenosine diphosphate $(\mathrm{ADP})$-receptor $\left(\mathrm{P}_{2} \mathrm{Y}_{12}\right)$ inhibitor is a cornerstone of the pharmacological treatment for patients with coronary artery disease undergoing percutaneous coronary intervention (PCI) [1].

Clopidogrel is one of the most widely used $\mathrm{P}_{2} \mathrm{Y}_{12}$ inhibitors, which undergoes a two-step metabolic transformation before binding to the platelet $\mathrm{P}_{2} \mathrm{Y}_{12}$ receptor [2]. Studies have shown wide variability of platelet clopidogrel response [3], indicating that a substantial proportion of patients have inappropriate platelet inhibition at a regular dose of clopidogrel $75 \mathrm{mg}$ once daily. It has been reported that high on-treatment platelet reactivity (HOPR) detected by platelet aggregometry leads to increased risk of thrombotic events [4-8], while low on-treatment platelet reactivity (LOPR) leads to increased risk of bleeding after PCI $[9,10]$. Thus, it is important to identify an optimal platelet inhibition or on-treatment platelet reactivity (PR) by platelet aggregometry $[11,12]$.

This study was to investigate an optimal therapeutic window for PR determined by light transmission aggregometry (LTA) to predict the lowest ischemic and bleeding risks in patients underwent PCI and treated with dual antiplatelet agents.

\section{Methods}

This is a prospective, single-center, registration study conducted at the First Affiliated Hospital of Nanjing Medical
University, Nanjing, China. The study was registered at URL: https://www.clinicaltrials.gov (Unique identifier: NCT019684 99) and was approved by the ethics committee of the First Affiliated Hospital of Nanjing Medical University. Written informed consent was obtained from each patient.

\section{Study population}

A total of 2768 patients were consecutively screened from April 2011 to October 2016 in the First Affiliated Hospital of Nanjing Medical University, among which 883 declined to participate, and the remaining 1885 patients were enrolled in the study (Fig. 1).

The inclusion criteria were patients who had undergone coronary stent implantation and taken aspirin $100 \mathrm{mg}$ in combination with clopidogrel $75 \mathrm{mg}$ daily for $>5$ days [7]. Exclusion criteria were patients: 1 ) intolerant to aspirin or clopidogrel (e.g. history of allergic reactions or gastrointestinal bleeding); 2) taking any other antiplatelet agents in addition to aspirin and clopidogrel (e.g. cilostazol); 3) taking any anticoagulant agents (e.g. vitamin $\mathrm{K}$ antagonists, new oral anticoagulants); 4) with myelodysplastic syndrome or abnormal baseline platelet counts of $<80 \times 10^{9}$ / $\mathrm{L}$ or $>450 \times 10^{9} / \mathrm{L}$; 5) with hemoglobin $\left.<90 \mathrm{~g} / \mathrm{L} ; 6\right)$ with cancer or any other complications that may not suitable to be recruited at the discretion of the investigators.

\section{PR measurements}

Six milliliter venous blood was collected into $3.2 \%$ citrate vacutainer tubes in the morning $2 \mathrm{~h}$ after the patients'

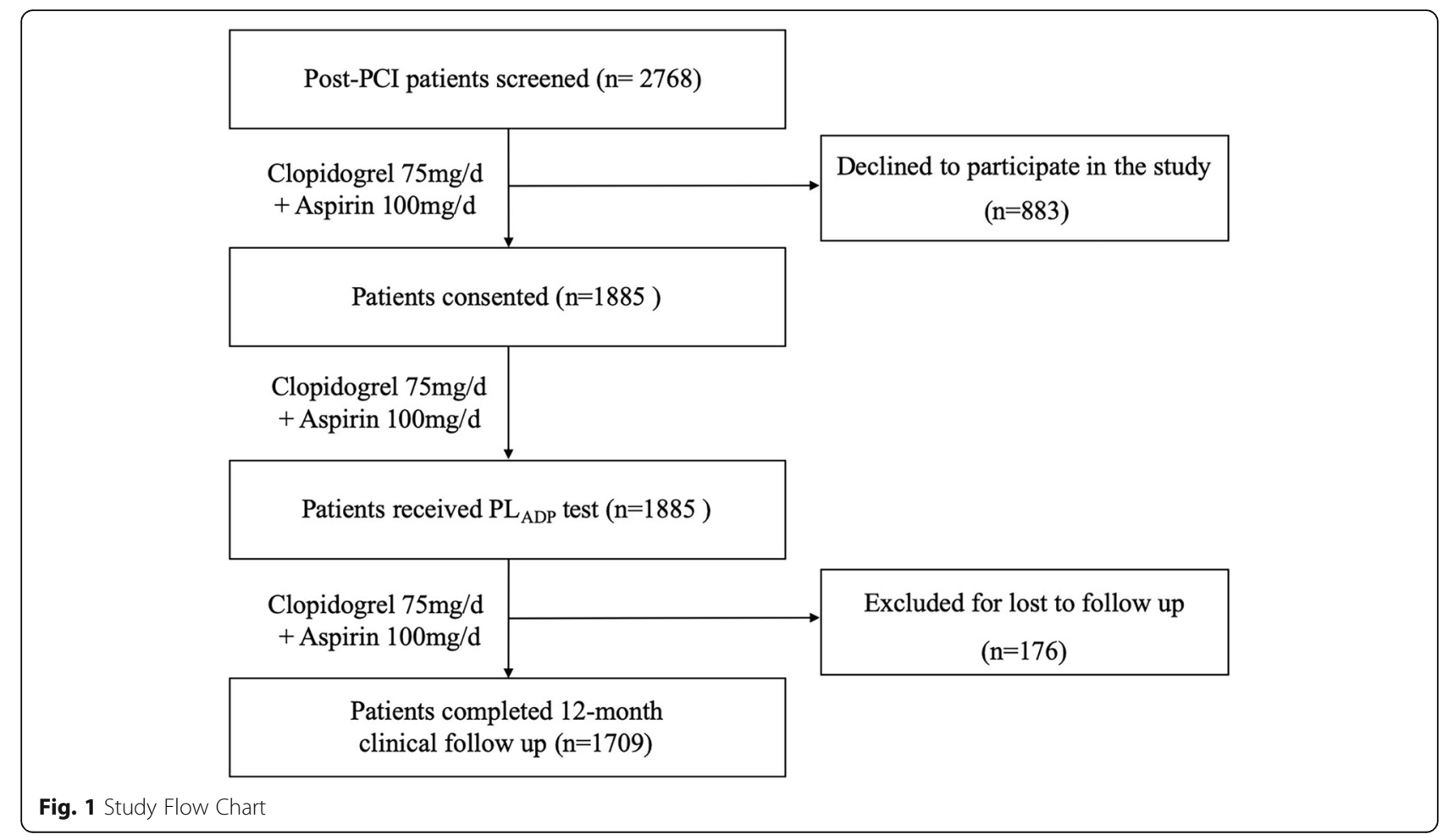


taking clopidogrel (if glycoprotein (GP) IIb/IIIa inhibitors were used, testing would be performed $24 \mathrm{~h}$ after drug discontinuation). Blood samples were subjected to platelet function test by LTA within $2 \mathrm{~h}$ as previously described [13]. In brief, samples were centrifuged at $200 \mathrm{~g}$ for $8 \mathrm{~min}$ to obtain platelet-rich plasma (PRP). Plateletpoor plasma (PPP) was prepared by centrifuging the remaining blood at $2465 \mathrm{~g}$ for $10 \mathrm{~min}$. Platelet counts were adjusted by the addition of PPP to the PRP to achieve a count of $250 \times 10^{9} / \mathrm{L}$. The ADP-induced platelet aggregation $\left(\mathrm{PL}_{\mathrm{ADP}}\right)$ was recorded using the maximum platelet aggregation within $8 \mathrm{~min}$ after addition of ADP (final concentration $5 \mu \mathrm{mol} / \mathrm{L}$ ) by a Chronolog Model 700 aggregometer (Chrono-log Corporation, Havertown, PA, USA) [13].

\section{Study end-points}

The primary end-point was set as the net adverse clinical events (NACE), a composite of ischemic events including cardiovascular death, nonfatal myocardial infarction (MI), target vessel revascularization (TVR), stent thrombosis (ST) and any bleeding defined by the Thrombolysis in Myocardial Infarction (TIMI) criteria [14]. MI was defined in accordance with the Third Universal Definition proposed in 2007 [15]. ST was defined as definite or probable according to the Academic Research Consortium definitions [16]. All the clinical events were independently adjudicated by two investigators blinded to the results of PR tests. Disagreements were resolved by discussion or consultation with a third investigator $(\mathrm{Li})$.

The outcome data were collected by 2 investigators who were blinded to the results of platelet reactivity testing. The patients were followed up in the clinic and less preferably by telephone call if they were unable to attend the clinic. A standard case report form was used to record the outcome.

\section{Statistical analysis}

Statistical analysis was performed using SPSS 22.0 software (SPSS, Chicago, IL, USA). Continuous variables are expressed as means \pm standard deviations (SD) or medians (range [or Inter Quartile Range]). Categorical variables are expressed as frequencies and percentages. Two-sided Mann-Whitney tests were used to compare $\mathrm{PL}_{\mathrm{ADP}}$ between groups. The time to primary endpoint between groups was compared using the Kaplan-Meier method. Survival curves were compared using the logrank test and hazard ratios were calculated using Cox's regression models. Sensitivity and specificity of $\mathrm{PL}_{\mathrm{ADP}}$ in predicting thrombotic events were calculated at different thresholds by receiver operating characteristic (ROC) curve analysis. A two-sided $P<0.05$ was statistically significant.

\section{Results}

Among the enrolled patients, 1709 completed the 12month clinical follow-up (Fig. 1). There were 45 (2.6\%) ischemic events and 328 (19.2\%) bleeding events. Ischemic events included 20 deaths, $20 \mathrm{MI}, 21 \mathrm{ST}$ and 11 TVR. Bleeding events included 5 major bleeding, 27 minor bleeding and 296 minimal bleeding.

\section{Relationship between PR and 1-year outcome}

The average time from PCI to PR test reached 2.50 days. Patients with ischemic events during follow-up had a higher $\mathrm{PL}_{\mathrm{ADP}}$ level compared to those without $(36 \%$ [IQR: $25-45$ ] vs.29\% [IQR: 20-40]; $P=0.054)$. ROC analysis was performed to evaluate the value of $\mathrm{PL}_{\mathrm{ADP}}$ in predicting ischemic events. As a result, a $\mathrm{PL}_{\mathrm{ADP}}$ cut-off value of $37.5 \%$ provided a sensitivity of $48.9 \%$, specificity of $70 \%$, and the largest area under the curve value of 0.58 (Fig. 2a). By comparison, the recommended cut-off value of $46 \%$ by LTA provides a sensitivity of $20 \%$ and a specificity of $84.3 \%$ [12]. While adopting $37.5 \%$ as a new cut-off value, 521 patients (30.5\%) were defined with HOPR, who experienced a higher rate of ischemic events compared with those without $(4.2 \%$ vs. $1.9 \% ; P=0.007$, Fig. 3a).

On the other hand, patients who experienced bleeding events had significantly lower $\mathrm{PL}_{\mathrm{ADP}}$ compared with those without bleeding (25\% [IQR 18-38] vs.30\% [IQR 21-41]; $P<0.001)$. By ROC analysis, a cut-off value of $25.5 \%$ provided a sensitivity of $50.3 \%$, a specificity of $62.6 \%$, and the largest area under the curve of 0.57 in predicting bleeding (Fig. 2b). Using this new cut-off value, 682 (39.9\%) patients were defined with LOPR, who experienced a higher rate of bleeding events compared to those without $(24.2 \%$ vs. $15.9 \%$; $P<0.001$, Fig. 3b).

The risk of ischemic events and NACE was nonsignificantly higher in patients with HOPR compared with those in normal responders $(4.2 \%$ vs. $2.2 \%$; HR $1.99 ; P=0.063$ and $19.8 \%$ vs. $16.8 \%$; HR $1.19 ; P=0.247$, for ischemic events and NACE, respectively) (Table 1, Fig. 4), while the risk of total bleeding and NACE was significantly higher in patients with LOPR compared with those in normal responders $(24.2 \%$ vs. $15.8 \%$; HR 1.61; $P=0.001$ and $25.7 \%$ vs. $16.8 \%$; HR $1.64 ; P<0.001$, for bleeding and NACE, respectively) (Table 1, Fig. 4).

\section{Optimal PR or therapeutic window of PR to prevent ischemic and bleeding events}

According to the ROC curve analysis, we defined an optimal window of $\mathrm{PL}_{\mathrm{ADP}}$ between 25.5 and $37.5 \%$ after dual antiplatelet treatment. As a result, $29.6 \%$ of the study population was comprised within this therapeutic window in this study. 

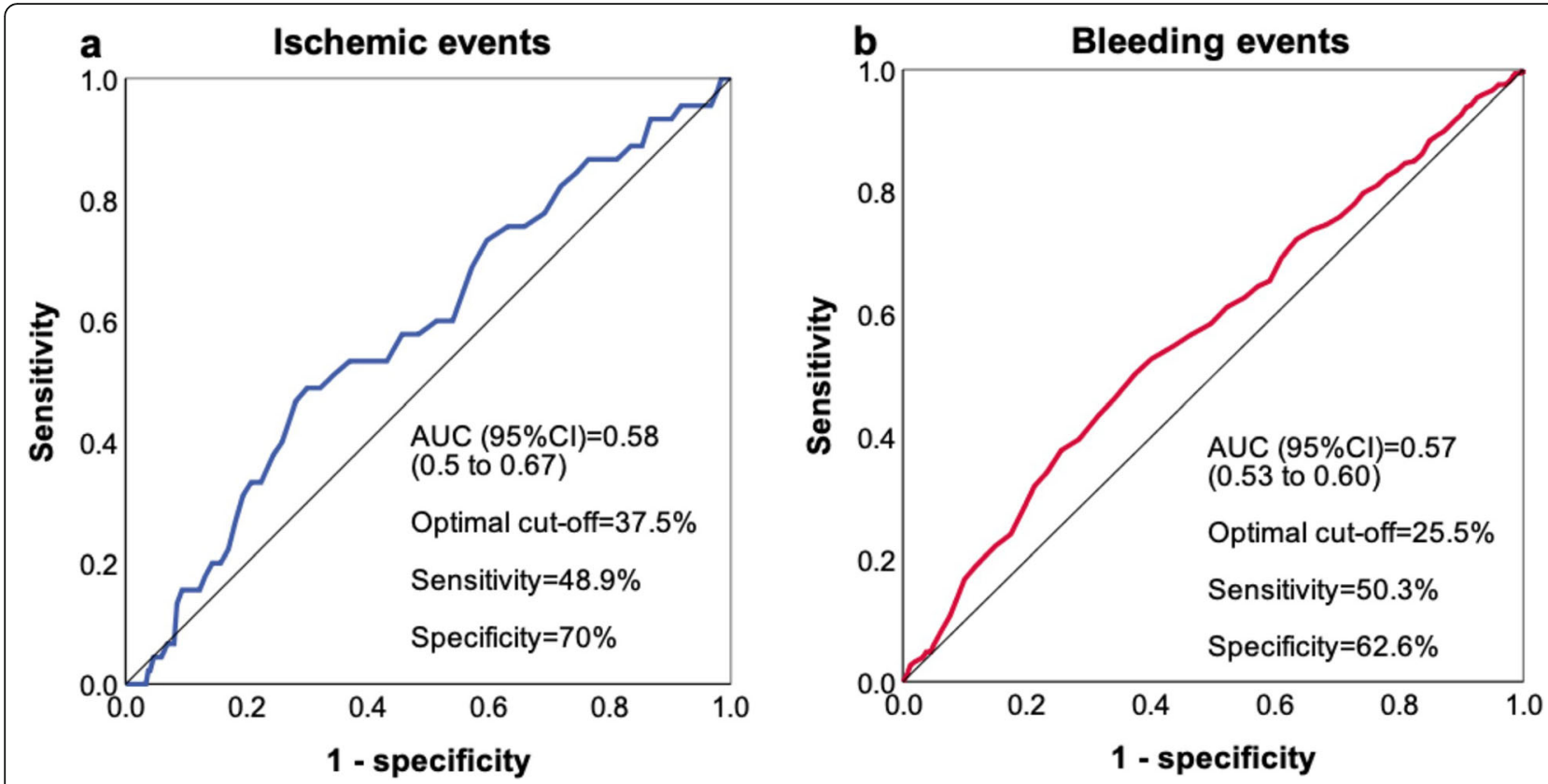

Fig. 2 ROC Curves for Ischemic and Bleeding Events. (a) Receiver operating characteristic (ROC) analysis for ischemic events. (b) ROC analysis for bleeding events. AUC, area under the curve; $\mathrm{Cl}$, confidence interval; $\mathrm{PL}_{\mathrm{ADP}}, \mathrm{ADP}$ induced platelet aggregation

We classified the patients into 2 groups according to PR: inside the window group (IW) $\left[\mathrm{PL}_{\mathrm{ADP}}(25.5-37.4 \%)\right]$ and outside the window group $(\mathrm{OW})\left(\mathrm{PL}_{\mathrm{ADP}}<25.5 \%\right.$ or $\geq 37.5 \%)$. The baseline demographic characteristics, clinical, angiographic and biological characteristics and medication history were described in Table 2. There were no significant differences in all the baseline characteristics between the 2 groups.

We further analyzed the prognosis according to the newly defined therapeutic window. The NACE rate of the IW group patients was lower than that of the
OW group patients $(16.8 \%$ vs. $23.1 \% ; P=0.004)$ (Fig. 3c). Kaplan-Meier analysis showed a significant difference in NACE and bleeding between patients within and outside the window, although no significant difference was found in ischemic events $(P=0.438$, 0.024 and 0.004 , for ischemic events, bleeding and NACE, respectively)(Fig. 5). The hazard ratio of NACE for OW group was significantly higher during the 12-month follow-up compared with IW group [1.44 (95\% CI: $1.12-1.85 ; P=0.004)$ ] after adjusting for age, gender, body mass index (BMI), history of
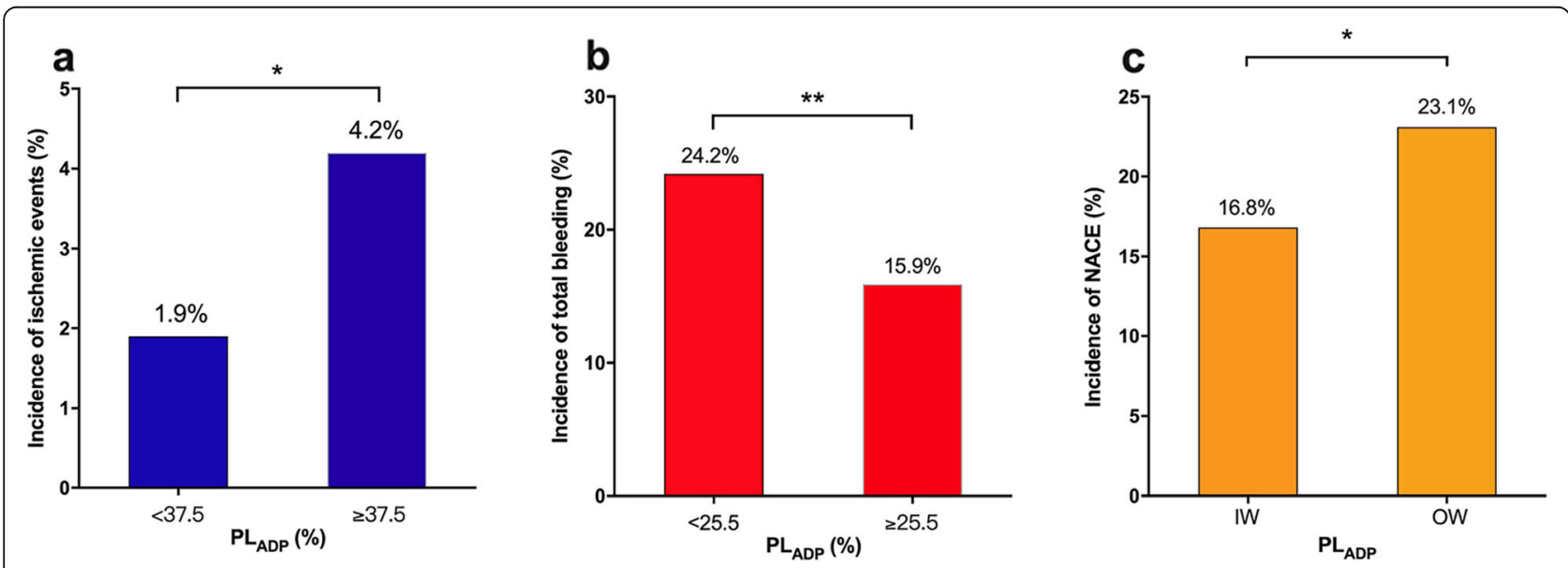

Fig. 3 Incidence of Ischemic, Bleeding Events and NACE Stratified by Platelet Reactivity. (a) Incidence of Ischemic events; (b) Incidence of Bleeding events; (c) Incidence of NACE. ${ }^{*} P<0.05$; ${ }^{*} P<0.001$. PL ADP, ADP induced platelet aggregation; NACE, net adverse clinical events; IW, inside the window; OW, outside the window 
Table 1 Multivariate analysis based on PLADP tri-classification

\begin{tabular}{|c|c|c|c|c|c|c|c|}
\hline \multirow[t]{3}{*}{ One-year outcome } & \multicolumn{7}{|l|}{$\mathrm{PL}_{\mathrm{ADP}}$} \\
\hline & \multirow{2}{*}{$\begin{array}{l}\text { Normal responder } \\
n=506 \\
n(\%)\end{array}$} & \multicolumn{3}{|l|}{$\begin{array}{l}\text { HOPR }^{\dagger} \\
n=521\end{array}$} & \multicolumn{3}{|l|}{$\begin{array}{l}\text { LOPR }^{\neq} \\
n=682\end{array}$} \\
\hline & & $n(\%)$ & $\mathrm{HR}(95 \% \mathrm{Cl})$ & $\mathbf{P}$ & $n(\%)$ & $\mathrm{HR}(95 \% \mathrm{Cl})$ & $P$ \\
\hline Net adverse clinical events & $85(16.8)$ & $103(19.8)$ & $1.19(0.89,1.61)$ & 0.247 & $175(25.7)$ & $1.64(1.25,2.14)$ & 0.000 \\
\hline Ischemic events & $11(2.2)$ & $22(4.2)$ & $1.99(0.96,4.10)$ & 0.063 & $12(1.8)$ & $0.83(0.37,1.89)$ & 0.660 \\
\hline Death & $5(1.0)$ & $12(2.3)$ & $2.34(0.82,6.66)$ & 0.111 & $3(0.4)$ & $0.45(0.11,1.88)$ & 0.273 \\
\hline $\mathrm{Ml}$ & $5(1.0)$ & $9(1.7)$ & $1.78(0.60,5.31)$ & 0.303 & $6(0.9)$ & $0.93(0.28,3.05)$ & 0.903 \\
\hline ST & $5(1.0)$ & $11(2.1)$ & $2.23(0.77,6.43)$ & 0.138 & $5(0.7)$ & $0.78(0.23,2.70)$ & 0.693 \\
\hline TVR & $1(0.2)$ & $6(1.2)$ & $5.86(0.70,48.86)$ & 0.102 & $4(0.6)$ & $3.33(0.37,29.89)$ & 0.282 \\
\hline Bleeding events & $80(15.8)$ & $83(16.1)$ & $0.99(0.73,1.36)$ & 0.967 & $165(24.2)$ & $1.61(1.23,2.12)$ & 0.001 \\
\hline Major + Minor & $10(2.0)$ & $5(1.0)$ & $0.47(0.16,1.39)$ & 0.172 & $17(2.5)$ & $1.17(0.53,2.60)$ & 0.701 \\
\hline Minimal & 70 (13.8) & $78(15.1)$ & $1.09(0.78,1.52)$ & 0.603 & $148(21.7)$ & $1.59(1.19,2.13)$ & 0.002 \\
\hline
\end{tabular}

Risk factors included in the analysis of net clinical outcome: Sex, age, BMI, Smoking, Hypertension, Diabetes, CABG history, PCI history, Hemoglobin, Platelet count, eGFR, APTT, INR; Risk factors included in the analysis of MACE: Sex, Age, BMI, Smoking, Hypertension, Diabetes, CABG history, PCI history; Risk factors included in the analysis of bleeding: Sex, Age, Hypertension, Diabetes, Hemoglobin, Platelet count, eGFR, INR, APTT

*Normal responder: $25.5 \% \leq \mathrm{PL}_{\mathrm{ADP}}<37.5 \%$ (control group); ${ }^{\dagger} \mathrm{HOPR}: \mathrm{PL}_{\mathrm{ADP}} \geq 37.5 \%$; ${ }^{\ddagger} \mathrm{LOPR}: \mathrm{PL}_{\mathrm{ADP}}<25.5 \%$

$P L_{A D P}$ ADP induced platelet aggregation, $H O P R$ high on-treatment platelet reactivity, $L O P R$ low on-treatment platelet reactivity, $H R$ hazard ratio, $C I$ confidence interval, $M I$ myocardial infarction, ST stent thrombosis, TVR target vessel revascularization, $B M I$ body mass index, $C A B G$ coronary artery bypass grafting, $P C I$ percutaneous coronary intervention, eGFR estimated glomerular filtration rate, $A P T T$ activated partial thromboplastin time, INR international normalized ratio

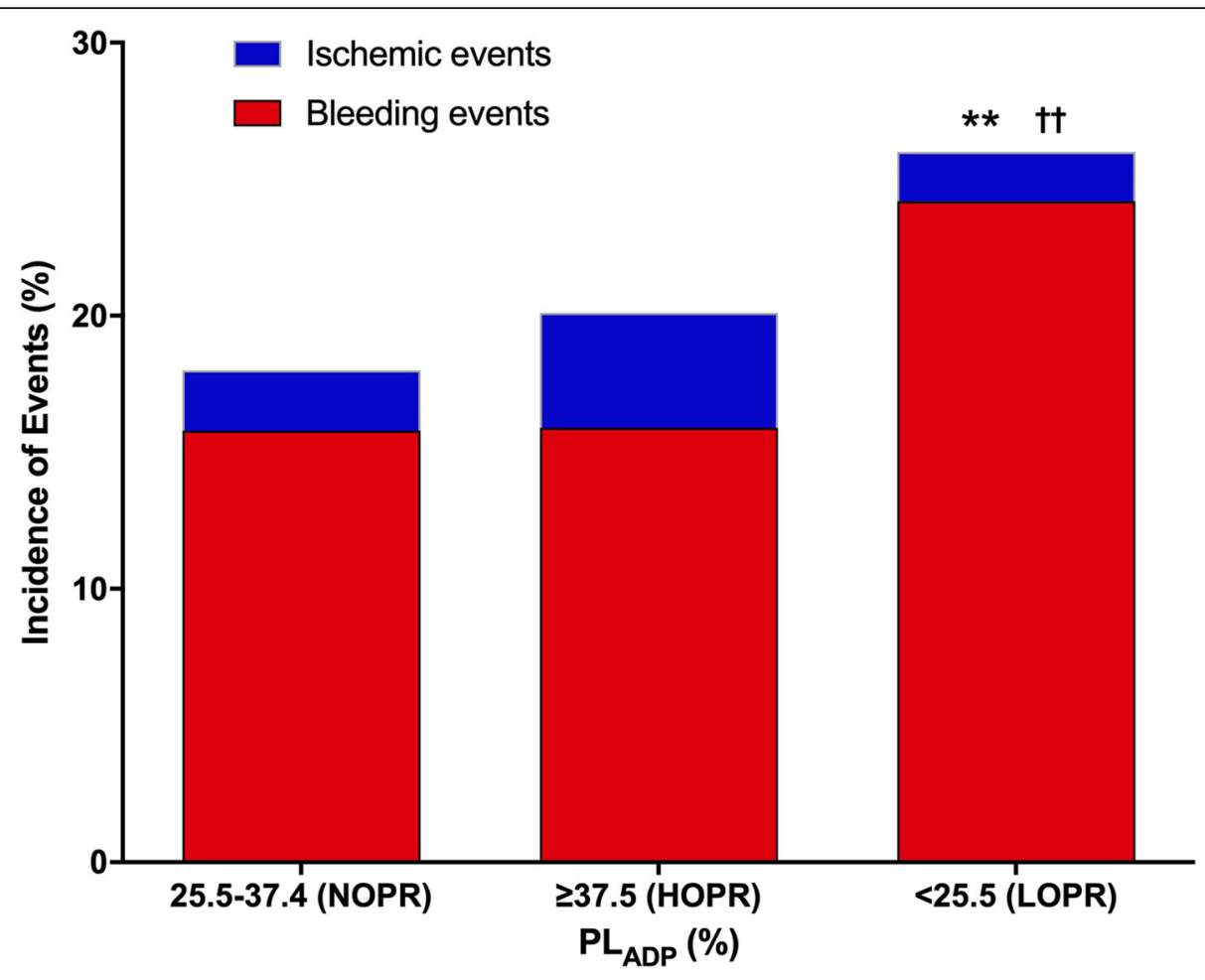

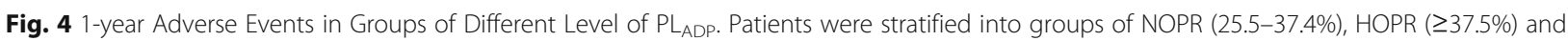
LOPR ( $<25.5 \%)$. ** represents $P<0.001$ for bleeding events compared with the NOPR group. †† represents $P<0.001$ for net adverse clinical events compared with the NOPR group. $\mathrm{PL}_{\mathrm{ADP}}$, ADP induced platelet aggregation; NOPR, normal on-treatment platelet reactivity; HOPR, high ontreatment platelet reactivity; LOPR, low on-treatment platelet reactivity 
Table 2 Baseline characteristics and medications

\begin{tabular}{|c|c|c|c|}
\hline & IW* & ow† & $P$ \\
\hline & $n=506$ & $n=1203$ & \\
\hline Age & $65(58,72)$ & $64(56,71)$ & 0.104 \\
\hline Gender (\%) & 74.70 & 75.40 & 0.763 \\
\hline BMI $\left(\mathrm{kg} / \mathrm{cm}^{2}\right)$ & $24.73(22.84,26.60)$ & $24.51(22.76,26.54)$ & 0.702 \\
\hline History of CABG (\%) & 1.20 & 0.70 & 0.376 \\
\hline History of $\mathrm{PCl}(\%)$ & 10.50 & 8.10 & 0.122 \\
\hline \multicolumn{4}{|l|}{ Cardiovascular risk factor } \\
\hline Smoking (\%) & 46.20 & 46.30 & 0.983 \\
\hline Hypertension (\%) & 68.00 & 64.70 & 0.188 \\
\hline Diabetes (\%) & 26.50 & 25.10 & 0.551 \\
\hline \multicolumn{4}{|c|}{ Angiography and intervention } \\
\hline SYNTAX score & $15(9,21.50)$ & $15(9,21.50)$ & 0.44 \\
\hline Length of stent & $39(24,66)$ & $39(24,62)$ & 0.856 \\
\hline Number of stent & $2(1,3)$ & $2(1,3)$ & 0.737 \\
\hline \multicolumn{4}{|l|}{ Biology } \\
\hline $\mathrm{HB}(\mathrm{g} / \mathrm{L})$ & $136(125,146)$ & $136(125,146)$ & 0.988 \\
\hline $\operatorname{PLT}\left(\times 10^{9}\right)$ & $186(157,227)$ & $186(155,222)$ & 0.996 \\
\hline LDL (mmol/L) & $2.57(2.06,3.24)$ & $2.49(2.04,3.12)$ & 0.382 \\
\hline eGFR (ml/min.1.732) & $89.51(77.34,103.95)$ & $89.59(76.43,104.85)$ & 0.93 \\
\hline APTT (s) & $25.90(23.50,28.40)$ & $25.70(23.60,28.20)$ & 0.787 \\
\hline INR & $1.02(0.98,1.07)$ & $1.02(0.98,1.06)$ & 0.609 \\
\hline \multicolumn{4}{|l|}{ Medications } \\
\hline ACEI/ARB (\%) & 57.70 & 56.20 & 0.564 \\
\hline$\beta$ blocker (\%) & 66.80 & 65.10 & 0.497 \\
\hline Statin (\%) & 96.40 & 96.20 & 0.815 \\
\hline Ilb/Illa inhibitor (\%) & 2.20 & 1.20 & 0.108 \\
\hline \multicolumn{4}{|c|}{$\begin{array}{l}\text { Data are presented as median (interquartile range) or percentage as } \\
\text { appropriate. * } \mathrm{IW}: 25.5 \% \leq \mathrm{PL} \mathrm{L}_{\mathrm{ADP}}<37.5 \% \text {; } \dagger \mathrm{OW}: \mathrm{PL} \mathrm{L}_{\mathrm{ADP}}<25.5 \% \text { or } \geq 37.5 \% \\
I W \text { inside the window, } \mathrm{OW} \text { outside the window, } B M I \text { body mass index, } C A B G \\
\text { coronary artery bypass grafting, } P C I \text { percutaneous coronary intervention, } M A C E \\
\text { major adverse clinical events, } H B \text { Hemoglobin, } P L T \text { platelet count, } L D L \text { low } \\
\text { density lipoprotein, eGFR estimated glomerular filtration rate, } A P T \text { activated } \\
\text { partial thromboplastin time, INR international normalized ratio, } A C E I / A R B \\
\text { angiotension converting enzyme inhibitors/ angiotension receptor blocker, Ilb/ } \\
\text { IIIa glycoprotein IIb/llla inhibitors }\end{array}$} \\
\hline
\end{tabular}

smoking, hypertension, diabetes, coronary artery bypass grafting (CABG), PCI, hemoglobin, platelet count, estimated glomerular filtration rate (eGFR), activated partial thromboplastin time (APTT), and international normalized ratio (INR) (Table 3). The total bleeding rate was also significantly higher in OW than IW after adjusting for the confounders [1.33 (95\% CI: $1.03-1.72 ; P=0.028)$ ], which turned out to be the main contributor to NACE (Table 3).

\section{Discussion}

In this study, we identified an optimal range of platelet reactivity as $25.5-37.4 \%$ for $\mathrm{PL}_{\mathrm{ADP}}$ while determined by LTA for patients underwent PCI and on the treatment of regular-dose aspirin and clopidogrel, and approximately one third (29.6\%) of the patients meet this therapeutic window. Patients inside the window presented significantly lower risk of NACE than those outside the window during 12-month follow-up.

Several studies have tried to identify a threshold of PR that could stratify patients at risk of ischemic events. Bliden et al. [17] found that HOPR (defined as $\mathrm{PL}_{\mathrm{ADP}} \geq$ $50 \%$ measured by LTA with ADP concentration of $5 \mu \mathrm{mol} / \mathrm{L}$ ) was the only variable being significantly related to ischemic events after adjusting for hypertension, diabetes and use of calcium channel inhibitors. Gurbel et al. [6] demonstrated that HOPR (defined as $\mathrm{PL}_{\mathrm{ADP}} \geq$ $46 \%$ measured by LTA [12] with ADP concentration of $5 \mu \mathrm{mol} / \mathrm{L}$ ) was an independent risk factor for ischemic events within 2 years of non-emergent PCI $(\mathrm{OR}=3.9$, $P<0.001$ ).

The cut-off value of $\mathrm{PL}_{\mathrm{ADP}}$ in our study is $37.5 \%$, which is lower than the previous study. However, as demonstrated by the GRAVITAS trial, when HOPR was defined as $\geq 230 \mathrm{P}^{2} \mathrm{Y}_{12}$ reaction units (PRU) by VerifyNow P2Y 12 test, high-dose clopidogrel compared with standard-dose clopidogrel did not reduce the incidence of major adverse cardiovascular events [18], while the post-hoc analysis found that the achievement of a PRU $<208$ was associated with significantly improved clinical
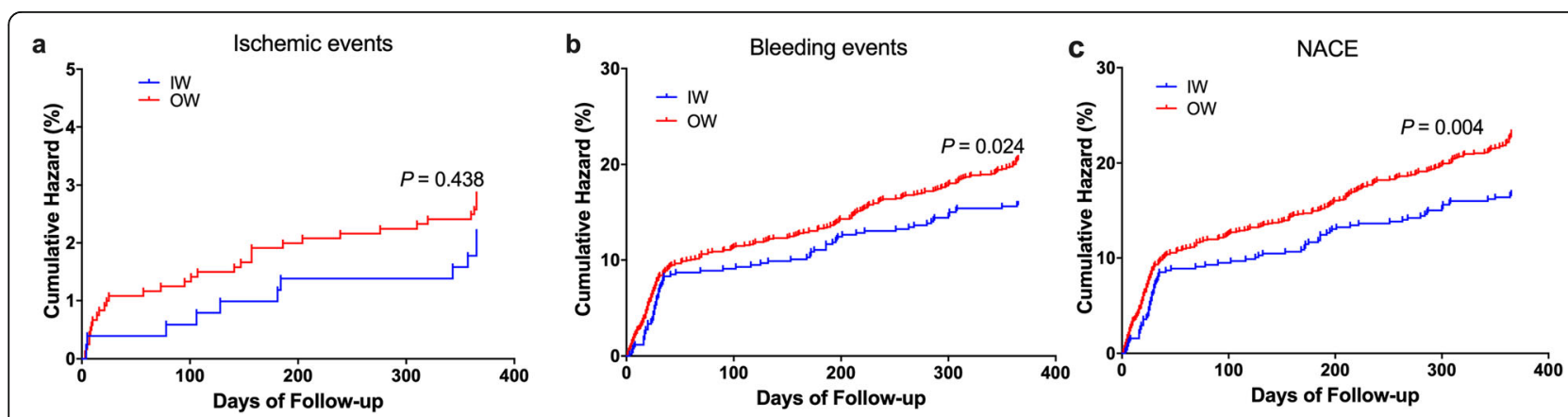

Fig. 5 Kaplan-Meier Analysis of Clinical Events. (a) Kaplan-Meier Analysis of Ischemic events; (b) Kaplan-Meier Analysis of Bleeding events; (c) Kaplan-Meier Analysis of NACE. NACE, net adverse clinical events; IW, inside the window; OW, outside the window 
Table 3 Multivariate analysis based on the therapeutic window

\begin{tabular}{llllll}
\hline One-year outcome & $\mathbf{I W}^{\mathbf{*}}$ & $\mathbf{O W}^{\dagger}$ & $\mathbf{H R}$ & $\mathbf{9 5 \%} \mathbf{C l}$ & $\mathbf{P}$ \\
& $\mathbf{5 0 6}$ & $\mathbf{1 2 0 3}$ & & & \\
& $\mathbf{n}(\%)$ & $\mathbf{n}(\%)$ & & & \\
\hline Net adverse clinical & 85 & 278 & 1.44 & $1.12-1.85$ & 0.004 \\
events & $(16.8)$ & $(23.1)$ & & & \\
Ischemic events & $11(2.2)$ & $34(2.8)$ & 1.34 & $0.68-2.64$ & 0.403 \\
$\quad$ Death & $5(1.0)$ & $15(1.2)$ & 1.27 & $0.46-3.51$ & 0.640 \\
MI & $5(1.0)$ & $15(1.2)$ & 1.30 & $0.47-3.59$ & 0.608 \\
ST & $5(1.0)$ & $16(1.3)$ & 1.41 & $0.52-3.87$ & 0.500 \\
TVR & $1(0.2)$ & $10(0.8)$ & 4.49 & $0.57-$ & 0.150 \\
& & & & 35.17 & \\
Bleeding events & 80 & 248 & 1.33 & $1.03-1.72$ & 0.028 \\
& $(15.8)$ & $(20.6)$ & & & \\
Major + Minor & $10(2.0)$ & $221(1.8)$ & 0.86 & $0.40-1.84$ & 0.700 \\
Minimal & 70 & 226 & 1.38 & $1.05-1.81$ & 0.022 \\
& $(13.8)$ & $(18.8)$ & & & \\
\hline
\end{tabular}

Risk factors included in the analysis of net clinical outcome: Sex, age, BMI, Smoking, Hypertension, Diabetes, CABG history, PCI history, Hemoglobin, Platelet count, eGFR, APTT, INR; Risk factors included in the analysis of MACE: Sex, Age, BMI, Smoking, Hypertension, Diabetes, CABG history, PCI history; Risk factors included in the analysis of bleeding: Sex, Age, Hypertension, Diabetes, Hemoglobin, Platelet count, eGFR, INR, APTT

${ }^{*}$ IW: $25.5 \% \leq \mathrm{PL}_{\mathrm{ADP}}<37.5 \%$; ${ }^{\dagger} \mathrm{OW}: \mathrm{PL}_{\mathrm{ADP}}<25.5 \%$ or $\geq 37.5 \%$

outcomes. Consistent with the GRAVITAS trial, our result suggests that a lower cut-off value of $\mathrm{PL}_{\mathrm{ADP}}$ might bring more low responders to the intensified antiplatelet treatment and consequently reduce ischemic events.

In addition to recurrent ischemic events, the prognostic importance of bleeding complications following PCI has also been established. ADAPT-DES trial showed that HOPR (defined by $>208$ PRU, by VerifyNow P2 $\mathrm{Y}_{12}$ test) was inversely related to TIMI major bleeding (adjusted HR: $0.73,95 \% \mathrm{CI}: 0.61$ to $0.89, P=0.002$ ) [3]. Studies suggested a possible link between LOPR and bleeding [7-9, 18-23]. With the LTA method, Tsukahara et al. [24] found that high-responsiveness was the independent predictor of major bleeding in patients receiving drugeluting stents and treated with thienopyridine. Parodi et al. [25] reported that LOPR $\left(\mathrm{PL}_{\mathrm{ADP}}<40 \%, 10 \mu \mathrm{mol} / \mathrm{L}\right.$ ADP, LTA assay) were the independent predictor of bleeding events. Consistent with previous studies, we confirmed the predictive value of $\mathrm{PR}$ on the occurrence of bleeding events after PCI as measured with the LTA assay, and we suggested a cut-off value of $\mathrm{PL}_{\mathrm{ADP}}<25.5 \%$ to predict the bleeding events.

The optimal therapeutic window of $\mathrm{PL}_{\mathrm{ADP}}$ is uncertain, Campo [26] and Mangiacapra et al. [1] have reported two therapeutic windows for PR measured with the VerifyNow P2Y 12 assay. However, in Campo's study, they reported all clinical events (ischemic and bleeding) after 1 month and up to 1 year of follow-up. Patients with adverse events during the first month were excluded. In Mangiacapra's study, only short-term outcome of 1-month clinical events were analyzed. By contrast, using the two thresholds for ischemic and bleeding events, we found an optimal therapeutic window for $\mathrm{PL}_{\mathrm{ADP}}$ by LTA assay, ranging from 25.5 to $37.4 \%$, which was associated with the lowest 1-year incidence of NACE. To the best of our knowledge, our study was the first that use LTA method to demonstrate an optimal therapeutic window for $\mathrm{PL}_{\mathrm{ADP}}$ regarding the 1-year clinical outcome.

Our study has important clinical implications. According to the results, post-PCI evaluation of PR carries important prognostic information, and the antiplatelet treatment should be guided referring to optimal therapeutic window of PR instead of single cut-off value. In particular, for patients with HOPR and higher ischemic risk, more aggressive antiplatelet strategies might be useful. On the other hand, for patients with LOPR and higher bleeding risk, conservative antiplatelet therapies should also be indicated until PR falls within the desired range.

The present study has potential limitations. First, the limited funding support prevented us to perform another cohort to validate the study results. Thus, a prospective study would be needed before using such an assay to try to predict outcomes. Second, the sample size was modest, so we could not analyze the optimal ranges of platelet reactivity for different age groups. Third, platelet reactivity could vary while patients taking clopidogrel treatment for longer term. However, we could not further extend the time of platelet reactivity test due to the limited hospitalization period. Besides, patients would be on high risk of thrombotic events early after PCI, so clopidogrel response in early stage of stent implantation would be more important to overcome or predict the thrombotic events.

\section{Conclusion}

An optimal therapeutic window of $25.5-37.4 \%$ for $\mathrm{PL}_{\mathrm{ADP}}$ predicts the lowest risk of net adverse cardiovascular events, which could be referred for tailored antiplatelet treatment while using platelet aggregation assay by light transmittance aggregometry.

\section{Code availability}

Not applicable.

\section{Authors' contributions}

Jing Wang, Jing Wang, Tong Wang, Jiazheng Ma and Jianzhen Teng analyzed data and wrote the manuscript; Xiaofeng Zhang, Jing Wang, Qian Gu, Zekang Ye, Inam Ullah, Chuchu Tan, Samee Abdus, Lu Shi and Xiaoxuan Gong provided patients, collected data, and critically reviewed the manuscript; Chunjian Li designed the study and critically reviewed the manuscript. All authors approved the manuscript for submission. 


\section{Funding}

This work was supported by a grant from the National Natural Science Funding of China (81170181), a grant from the Jiangsu Province's Key Provincial Talents Program (ZDRCA2016013), the Second Level of 333 High Level Talent Training Project in Jiangsu Province (BRA2019099), the Special Fund for Key R \& D Plans (Social Development) of Jiangsu Province (BE2019754), and a Project Funded by the Priority Academic Program Development of Jiangsu Higher Education Institutes (PAPD).

\section{Availability of data and materials}

The datasets used or analyzed during the current study are available from the corresponding author on reasonable request.

\section{Declarations}

\section{Ethics approval and consent to participate}

This study was approved by the ethics committee of the First Affiliated Hospital of Nanjing Medical University based on the Declaration of Helsinki. Written informed consent was obtained from each patient.

\section{Consent for publication}

Written informed consent for publication was obtained from all participants.

\section{Competing interests}

The authors have no conflict of interest to declare.

\section{Author details}

'Departments of Cardiology, the First Affiliated Hospital of Nanjing Medical University, 300 Guangzhou Road, Nanjing 210029, Jiangsu, China. 2Department of Cardiology, the Affiliated Huaian No.1 People's Hospital of Nanjing Medical University, Huai'an, Jiangsu, China. ${ }^{3}$ Department of Cardiology, the First People's Hospital of Yancheng, Yancheng, Jiangsu, China. ${ }^{4}$ Department of Cardiology, the Second Hospital of Nanjing, Nanjing University of Chinese Medicine, Nanjing, Jiangsu, China.

Received: 16 June 2021 Accepted: 21 September 2021

Published online: 19 October 2021

\section{References}

1. Mangiacapra F, Patti G, Barbato E, Peace AJ, Ricottini E, Vizzi V, et al. A therapeutic window for platelet reactivity for patients undergoing elective percutaneous coronary intervention: results of the ARMYDA-PROVE (antiplatelet therapy for reduction of MYocardial damage during angioplasty-platelet reactivity for outcome validation effort) study. JACC Cardiovasc Interv. 2012:5(3):281-9. https://doi.org/10.1016/j.jcin.2012.01.009

2. Herbert JM, Savi P. P2Y12, a new platelet ADP receptor, target of clopidogrel. Semin Vasc Med. 2003;3(2):113-22. https://doi.org/10.1055/s-2 003-40669.

3. Stone GW, Witzenbichler B, Weisz G, Rinaldi MJ, Neumann FJ, Metzger DC, et al. Platelet reactivity and clinical outcomes after coronary artery implantation of drug-eluting stents (ADAPT-DES): a prospective multicentre registry study. Lancet. 2013;382(9892):614-23. https://doi.org/10.1016/s01406736(13)61170-8

4. Gurbel PA, Bliden KP, Saucedo JF, Suarez TA, DiChiara J, Antonino MJ, et al. Bivalirudin and clopidogrel with and without eptifibatide for elective stenting: effects on platelet function, thrombelastographic indexes, and their relation to periprocedural infarction results of the CLEAR PLATELETS-2 (Clopidogrel with Eptifibatide to arrest the reactivity of Platelets) study. J Am Coll Cardiol. 2009;53(8):648-57. https://doi.org/10.1016/j.jacc.2008.10.045.

5. Gurbel PA, Bliden KP, Samara W, Yoho JA, Hayes K, Fissha MZ, et al. Clopidogrel effect on platelet reactivity in patients with stent thrombosis: results of the CREST study. J Am Coll Cardiol. 2005;46(10):1827-32. https:// doi.org/10.1016/j.jacc.2005.07.056

6. Gurbel PA, Antonino MJ, Bliden KP, Dichiara J, Suarez TA, Singla A, et al. Platelet reactivity to adenosine diphosphate and long-term ischemic event occurrence following percutaneous coronary intervention: a potential antiplatelet therapeutic target. Platelets. 2008;19(8):595-604. https://doi. org/10.1080/09537100802351065.

7. Breet NJ, van Werkum JW, Bouman HJ, Kelder JC, Ruven HJ, Bal ET, et al. Comparison of platelet function tests in predicting clinical outcome in patients undergoing coronary stent implantation. JAMA. 2010;303(8):754-62. https://doi.org/10.1001/jama.2010.181

8. Cuisset T, Frere C, Quilici J, Gaborit B, Castelli C, Poyet R, et al. Predictive values of post-treatment adenosine diphosphate-induced aggregation and vasodilator-stimulated phosphoprotein index for stent thrombosis after acute coronary syndrome in clopidogrel-treated patients. Am J Cardiol. 2009;104(8):1078-82. https://doi.org/10.1016/j.amjcard.2009.06.007.

9. Patti G, Pasceri V, Vizzi V, Ricottini E, Di Sciascio G. Usefulness of platelet response to clopidogrel by point-of-care testing to predict bleeding outcomes in patients undergoing percutaneous coronary intervention (from the antiplatelet therapy for reduction of myocardial damage during angioplasty-bleeding study). Am J Cardiol. 2011;107(7):995-1000. https://doi. org/10.1016/j.amjcard.2010.11.025.

10. Sibbing D, Steinhubl SR, Schulz S, Schömig A, Kastrati A. Platelet aggregation and its association with stent thrombosis and bleeding in clopidogrel-treated patients: initial evidence of a therapeutic window. J Am Coll Cardiol. 2010;56(4):317-8. https://doi.org/10.1016/j.jacc.2010.03.048.

11. Price MJ. Bedside evaluation of thienopyridine antiplatelet therapy. Circulation. 2009;119(19):2625-32. https://doi.org/10.1161/circulationaha.107. 696732.

12. Bonello L, Tantry US, Marcucci R, Blindt R, Angiolillo DJ, Becker R, et al. Consensus and future directions on the definition of high on-treatment platelet reactivity to adenosine diphosphate. J Am Coll Cardiol. 2010;56(12): 919-33. https://doi.org/10.1016/j.jacc.2010.04.047.

13. Li C, Hirsh J, Xie C, Johnston MA, Eikelboom JW. Reversal of the anti-platelet effects of aspirin and clopidogrel. J Thromb Haemost. 2012;10(4):521-8. https://doi.org/10.1111/j.1538-7836.2012.04641.x.

14. Rao AK, Pratt C, Berke A, Jaffe A, Ockene I, Schreiber TL, et al. Thrombolysis in myocardial infarction (TIMI) trial--phase I: hemorrhagic manifestations and changes in plasma fibrinogen and the fibrinolytic system in patients treated with recombinant tissue plasminogen activator and streptokinase. J Am Coll Cardiol. 1988;11(1):1-11. https://doi.org/10.1016/0735-1097(88)90158-1.

15. Thygesen K, Alpert JS, White HD. Universal definition of myocardial infarction. J Am Coll Cardiol. 2007;50(22):2173-95. https://doi.org/10.1016/j.ja cc.2007.09.011.

16. Cannon CP, Battler A, Brindis RG, Cox JL, Ellis SG, Every NR, et al. American College of Cardiology key data elements and definitions for measuring the clinical management and outcomes of patients with acute coronary syndromes. A report of the American College of Cardiology Task Force on clinical data standards (acute coronary syndromes writing committee). J Am Coll Cardiol. 2001;38(7):2114-30. https://doi.org/10.1016/s0735-1097(01)01 702-8.

17. Bliden KP, DiChiara J, Tantry US, Bassi AK, Chaganti SK, Gurbel PA. Increased risk in patients with high platelet aggregation receiving chronic clopidogrel therapy undergoing percutaneous coronary intervention: is the current antiplatelet therapy adequate? J Am Coll Cardiol. 2007;49(6):657-66. https:// doi.org/10.1016/j.jacc.2006.10.050.

18. Price MJ, Berger PB, Teirstein PS, Tanguay JF, Angiolillo DJ, Spriggs D, et al. Standard- vs high-dose clopidogrel based on platelet function testing after percutaneous coronary intervention: the GRAVITAS randomized trial. JAMA. 2011;305(11):1097-105. https://doi.org/10.1001/jama.2011.290.

19. SIBBING D, SCHULZ S, BRAUN S, MORATH T, STEGHERR J, Mehilli J, et al. Antiplatelet effects of clopidogrel and bleeding in patients undergoing coronary stent placement. 2010;8(2):250-6. https://doi.org/10.1111/j.15387836.2009.03709.x

20. BONELLO L, MANCINI J, PANSIERI M, MAILLARD L, ROSSI P, COLLET F, et al. Relationship between post-treatment platelet reactivity and ischemic and bleeding events at 1-year follow-up in patients receiving prasugrel. 2012; 10(10):1999-2005. https://doi.org/10.1111/j.1538-7836.2012.04875.x.

21. Collet J-P, Cuisset T, Rangé G, Cayla G, Elhadad S, Pouillot C, et al. Bedside Monitoring to Adjust Antiplatelet Therapy for Coronary Stenting. 2012; 367(22):2100-9. https://doi.org/10.1056/NEJMoa1209979.

22. Gurbel PA, Bliden KP, Navickas IA, Mahla E, Dichiara J, Suarez TA, et al. Adenosine diphosphate-induced platelet-fibrin clot strength: A new thrombelastographic indicator of long-term poststenting ischemic events. Am Heart J. 2010;160(2):346-54. https://doi.org/10.1016/j.ahj.2010.05.034.

23. Mokhtar OA, Lemesle G, Armero S, Mancini J, Bonello C, Tahirou I, et al. Relationship between platelet reactivity inhibition and non-CABG related major bleeding in patients undergoing percutaneous coronary intervention. Thromb Res. 2010;126(2):e147-e9. https://doi.org/10.1016/j. thromres.2010.01.013. 
24. Tsukahara K, Kimura K, Morita S, Ebina T, Kosuge M, Hibi K, et al. Impact of high-responsiveness to dual antiplatelet therapy on bleeding complications in patients receiving drug-eluting stents. Circ J. 2010;74(4):679-85. https:// doi.org/10.1253/circj.cj-09-0601.

25. Parodi G, Bellandi B, Venditti F, Carrabba N, Valenti R, Migliorini A, et al. Residual platelet reactivity, bleedings, and adherence to treatment in patients having coronary stent implantation treated with prasugrel. Am J Cardiol. 2012;109(2):214-8. https://doi.org/10.1016/j.amjcard.2011.08.034.

26. Campo G, Parrinello G, Ferraresi P, Lunghi B, Tebaldi M, Miccoli M, et al. Prospective evaluation of on-clopidogrel platelet reactivity over time in patients treated with percutaneous coronary intervention relationship with gene polymorphisms and clinical outcome. J Am Coll Cardiol. 2011;57(25): 2474-83. https://doi.org/10.1016/j.jacc.2010.12.047.

\section{Publisher's Note}

Springer Nature remains neutral with regard to jurisdictional claims in published maps and institutional affiliations.

Ready to submit your research? Choose BMC and benefit from:

- fast, convenient online submission

- thorough peer review by experienced researchers in your field

- rapid publication on acceptance

- support for research data, including large and complex data types

- gold Open Access which fosters wider collaboration and increased citations

- maximum visibility for your research: over $100 \mathrm{M}$ website views per year

At BMC, research is always in progress.

Learn more biomedcentral.com/submissions 